\title{
Analysis of Influence Factors of GF-4 Registration Accuracy on Sea Ice Drift in the Bohai Sea
}

\author{
Wang Ruifu, Wei Pan, Zhao Yingjie \\ College of Geomatics, Shandong University of Science and Technology, 266590, Qingdao, China;
}

\begin{abstract}
The "GF-4" satellite is China's first high resolution geostationary optical remote sensing satellite. It has the unique advantages of short imaging time interval $(20 \mathrm{~s})$ and high resolution $(50 \mathrm{~m})$. In order to analyze the effect of GF-4 satellite image registration accuracy on sea ice drift in Bohai Sea, firstly, the orthorectification of the 28 image data available from August 2016 to March 2018 in the Bohai Sea area was carried out. Then we selected the sea-land edge points as control points, and registration of two images which have the same time interval. Next, we recorded the marked same name points which searched from the bottom of Liaodong bay, east of Liaodong bay and west of Liaodong bay respectlly. We statisticed the direction and frequency of land point offset sub-regionally, then we created the rose plots and maked histogram of the offset of land point. The results show that, when the time interval is 4 hours and 24 hours, the dominant migration direction in the three regions in Liaodong bay is east; when the time interval is 1 minute, the dominant migration direction in Liaodong Bay bottom and Liaodong Bay west coast land is south, Followed by east and southeast respectively; the dominant migration in Liaodong Bay East Coast is north, followed by east; When the time interval is 3 hours, the dominant migration direction in west of Liaodong Bay, bottom of Liaodong Bay and east of Liaodong bay are east, west and south respectively, followed by southeast, east, southeast respectively. The land offset in three regions is major centralized distribution in a range which is from $60 \mathrm{~m}$ to $80 \mathrm{~m}$. That is to say, the offset of land is basically equal to 1.2 times of pixels, and the maximum land offset is less than 2 times of pixels. Through statistical analysis, it can be seen that with the increase of time interval, the land offset will not change much. This study also paves the way for the study of the drift of sea ice.
\end{abstract}

\section{INTRODUCTION}

The Bohai Sea is located in the middle lattitude region, and it is also one of the most severe ice conditions in China. The Bohai Sea and its surrounding waters are rich in large amounts of oil and natural gas, which occupies an important position in our national economy. However, there are different degrees of ice formation in the Bohai Sea in winter each year. The drift of sea ice and sea ice has caused major economic losses to China's economy, such as the destruction of sea structures, the blocking of shipping and the destruction of ships. Therefore, it is necessary to carry out relevant researches on sea ice drift monitoring in Bohai Sea. At present, scholars at home and abroad have carried out research on sea ice drift monitoring based on a variety of satellite images. The remote sensing data commonly used for polar sea ice monitoring include Microwave Scatterometers, Microwave Radiometers, and Synthetic Aperture Radar (SAR) [1-5]. Due to the severe seawater movement in the Bohai Sea, sea ice deformation is likely to occur. The revisit period of Microwave Scatterometers, Microwave Radiometers, and SARs is relatively long and cannot meet the demand for sea ice drift monitoring in the Bohai Sea. Some scholars have also conducted sea ice research using
Moderate Resolution Imaging Spectroradiometer (MODIS) and Geostationary Ocean Color Imager (GOCI) data, and successfully applied the data to the sea ice drift monitoring in the Bohai Sea. However, the "GF-4" satellite imaging time interval is 20 s and the resolution is $50 \mathrm{~m}$. It has a higher time resolution and spatial resolution and is more suitable for sea ice drift tracking. Xiao-ying Chen based on GF-4 satellite do the green tide extraction research drift velocity in Yellow Sea, Libo Yao studied ship target tracking based on GF-4 satellite [6], Zhongting Wang used GF-4 data monitoring "beijing-tianjinhebei region aerosol [7].There is little research on sea ice monitoring by the GF-4 satellite, and no one has performed error analysis. However, the error will lead to inaccurate sea ice drift velocity. This paper focuses on the analysis of the factors affecting the sea ice drift in the Bohai Sea by the accuracy of GF-4 satellite image registration.

\section{DATA SETS AND METHOD}

\subsection{Study Area}

The Bohai Sea is located at latitude $37^{\circ} 07^{\prime}-41^{\circ} 0^{\prime} \mathrm{N}$ and longitude $117^{\circ} 35^{\prime}-121^{\circ} 10^{\prime} \mathrm{E}$. which is composed of 
Liaodong Bay, Laizhou Bay, Bohai Bay and the central Bohai Sea, with varying degrees of freezing phenomenon each winter [8-9].

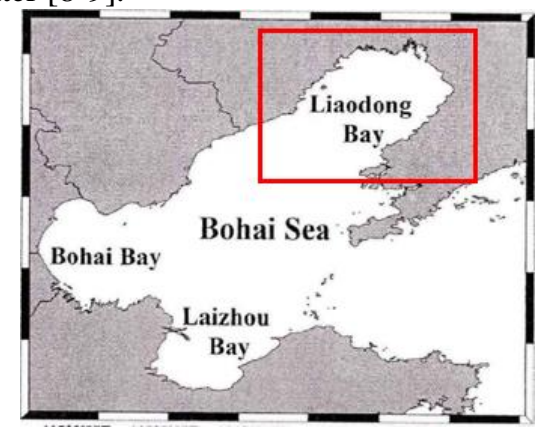

Figure 1 Liaodong Bay area of Bohai Sea

Liaodong Bay is the most frozen region in the north of China. It is also the earliest area of sea ice in Bohai Sea. The research area of this paper is the Liaodong Bay area of Bohai Sea, as shown in Fig. 1.

\subsection{GF-4 data}

The GF-4 satellite was successfully launched in December 2015 and officially put into use in June 2016. It is China's first high-resolution optical satellite in geostationary orbit, with a weighing about 5 tons and a design life of 8 years. And it is running at a geostationary orbit about 30,000 kilometers from the ground and located at the equator of 105. 6 degrees east longitude. It can perform large-scale observations on about one-third of the earth's surface and can continuously observe a certain area for a long period of time. The GF-4 satellite has configuration of the largest aperture array staring camera in our country, and the first large-area array infrared detector developed.

Table 1 Main technical indexes of GF-4 satellite and its payloads

\begin{tabular}{cc}
\hline Content & Indicators \\
\hline Satellite orbit & Geostationary orbit \\
Orbital & 36000 \\
altitude/km & $106.5^{\circ}$ \\
Designated & \\
location & 20 \\
Revisit time $/ \mathrm{s}$ & Visible light near infrared \\
\hline Remote sensor & channel: $0.45 \sim 0.90 \mu \mathrm{m}$, \\
spectrum & $0.45 \sim 0.52 \mu \mathrm{m}, 0.52 \sim$ \\
& $0.60 \mu \mathrm{m}, 0.63 \sim 0.69 \mu \mathrm{m}$, \\
& $0.76 \sim 0.90 \mu \mathrm{m} ;$ \\
& Medium wave infrared \\
channel: $3.5 \sim 4.1 \mu \mathrm{m}$ \\
\hline Image ground & Visible light near infrared \\
channel: $50 ;$ \\
pixel resolution. & Medium wave infrared \\
& channel: 400 \\
\hline
\end{tabular}

It has four working modes: census, gaze, area, and motor patrol. Visible light near-infrared channel pixel resolution ( The point below the star) has reached $50 \mathrm{~m}$ with four bands of blue, green, red and near-infrared, and the resolution of the mid-wave infrared channel pixel has reached $400 \mathrm{~m}$. Compared with traditional geostationary orbit satellites which has only 100 meters' observation capability, its rate has increased dramatically.
In addition, its time resolution is up to 20 s, and its high spatial-temporal resolution provides better data support for faster dynamic sea ice drift monitoring. The development of GF-4 satellite has opened up a new field of high-orbit high-resolution earth observation technology in China, represents the highest level of China's geostationary orbit satellites, and is also at the international advanced level [10]. The technical indicators of GF-4 satellite load are shown in Table 1.

Table 2 Information of the selected GF-4 images

\begin{tabular}{|c|c|c|c|}
\hline $\begin{array}{l}\text { The time } \\
\text { interval }\end{array}$ & $\begin{array}{l}\text { Date of } \\
\text { imaging }\end{array}$ & \multicolumn{2}{|c|}{$\begin{array}{l}\text { Imaging time (Beijing } \\
\text { time) }\end{array}$} \\
\hline \multirow[t]{4}{*}{$1 \mathrm{~min}$} & \multirow[t]{2}{*}{2017.1 .18} & $11: 04: 25$ & $11: 05: 34$ \\
\hline & & $11: 05: 34$ & $11: 06: 44$ \\
\hline & \multirow[t]{2}{*}{2017.3 .3} & $11: 10: 41$ & $11: 11: 48$ \\
\hline & & $11: 12: 55$ & $11: 14: 01$ \\
\hline \multirow[t]{2}{*}{$3 \mathrm{~h}$} & \multirow[t]{2}{*}{2017.1 .10} & $11: 31: 58$ & $14: 31: 58$ \\
\hline & & $11: 33: 37$ & $14: 33: 37$ \\
\hline \multirow[t]{4}{*}{$4 \mathrm{~h}$} & \multirow[t]{2}{*}{2017.1 .6} & $10: 31: 58$ & $14: 31: 58$ \\
\hline & & $10: 33: 37$ & $14: 33: 37$ \\
\hline & \multirow[t]{2}{*}{2017.1 .9} & $10: 32: 13$ & $14: 33: 37$ \\
\hline & & $10: 33: 52$ & $14: 31: 58$ \\
\hline \multirow[t]{6}{*}{$24 \mathrm{~h}$} & 2017.1 .9 & $14: 31: 58$ & $14: 33: 37$ \\
\hline & 2017.1 .10 & $14: 31: 58$ & $14: 33: 37$ \\
\hline & 2018.2 .3 & \multicolumn{2}{|l|}{ 10:00:42 } \\
\hline & 2018.2 .4 & \multicolumn{2}{|l|}{$10: 00: 42$} \\
\hline & 2018.2 .5 & \multicolumn{2}{|l|}{$10: 00: 42$} \\
\hline & 2018.2 .6 & \multicolumn{2}{|l|}{$10: 00: 42$} \\
\hline
\end{tabular}

From China resources satellite application center land observation satellite data service platform for the August 2016 to March 2018 can constitute a time series of sunny weather, high visibility, cloudless 28 scene GF - 4 satellite image as the research data of this paper (Table 2).

\subsection{Method}

The method used in this paper mainly includes two steps: (1) Ortho-rectification of 28 scene images respectively, and the corrected image adopts WGS-84 coordinate system and UTM projection. (2) Registration of the corrected image, the accuracy of registration is less than 0.5 pixels.

The original image is an L1A class product. Orthorectification is performed on the original image using ASTER GDEM data. ASTER GDEM is called the Advanced Spaceborne Thermal Emission and Reflection Radiometer Global Digital Elevation Model. It is the global digital elevation model of the advanced spaceborne thermal emission and reflection radiometer. Like the SRTM, it is a digital elevation DEM with a global spatial resolution of 30 meters. ASTER GDEM is downloaded from the Geospatial Data Cloud.

In the process of registering the corrected image, there 
will inevitably be errors. The Error include residual error and root mean square error. Normally, the accuracy of the registration is less than 0.5 pixels, and the resolution of the GF-4 image is 50 meters. Therefore, the total root mean square error is required to be less than 25 meters.

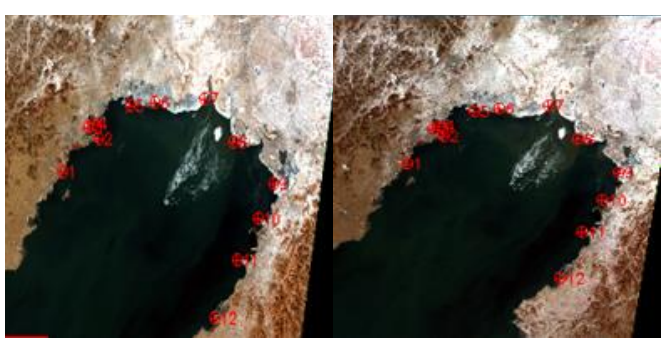

(a) The image at 10:33:52 (b) The image at 14:31:58

Figure 2 Image on January 9

Take the images of the two moments at 10:33:52 and 14:31:58 on January 9, 2017 (about 4 hours apart) as an example. As shown in Fig. 2, there are two images on January 9 after the orthorectification has been performed. Twelve control points were evenly selected for registration on the land edges of the two images. The total root mean square error of all control points was 0.422795 , and the residuals and root mean square errors of the control points during the registration were as shown in Table 3.

Table 3 The residual error and root-mean-square error of the two image control points at 10:33:52 and 14:31:58 on January 9

\begin{tabular}{cccccccccc}
\hline Point & BaseX & BaseY & WarpX & WarpY & PredictX & PredictY & ErrorX & ErrorY & RMS \\
\hline 1 & 628 & 1261 & 523 & 1068 & 522.92 & 1067.89 & -0.08 & -0.11 & 0.14 \\
2 & 935 & 1031 & 829.75 & 837.5 & 829.62 & 837.47 & -0.13 & -0.03 & 0.13 \\
3 & 850.5 & 959.5 & 745.5 & 765.75 & 745.02 & 765.94 & -0.48 & 0.19 & 0.52 \\
4 & 896.5 & 934 & 790.75 & 740.5 & 791 & 740.41 & 0.25 & -0.09 & 0.26 \\
5 & 1199.75 & 813.75 & 1094.5 & 620.25 & 1094.23 & 620.06 & -0.27 & -0.19 & 0.33 \\
6 & 1413.5 & 787.25 & 1307.25 & 593.5 & 1308.05 & 593.55 & 0.8 & 0.05 & 0.81 \\
7 & 1840 & 765.75 & 1734.5 & 571.75 & 1734.74 & 572.08 & 0.24 & 0.33 & 0.41 \\
8 & 2088.25 & 1057 & 1983.25 & 863 & 1983.08 & 862.97 & -0.17 & -0.03 & 0.17 \\
9 & 2435.25 & 1333.25 & 2330.5 & 1139 & 2330 & 1138.55 & -0.5 & -0.45 & 0.67 \\
10 & 2301 & 1571.25 & 2195.5 & 1376 & 2195.69 & 1376.29 & 0.19 & 0.29 & 0.35 \\
11 & 2120.25 & 1846.5 & 2015.25 & 1651.5 & 2014.98 & 1651.42 & -0.27 & -0.08 & 0.28 \\
12 & 1934 & 2244 & 1828.5 & 2048.75 & 1828.89 & 2048.86 & 0.39 & 0.11 & 0.41 \\
\hline
\end{tabular}

\section{PRECISION ANALYSIS}

Based on the above two images, the Liaodong Bay is divided into three areas: the bottom of Liaodong Bay, east coast of Liaodong Bay and west bank, as shown in Fig. 3. In each of the three regions, it is easy to identify the distinctive feature points, such as the intersection of the road and the corner of the field, etc. Recorded the coordinate information of the same feature point in the two images, and counted the differences in the $\mathrm{X}$ direction and $\mathrm{Y}$ direction as well as the total offset, offset direction and angle. Summarize all the statistical information of 4 hours inteval, and make the rose diagram for the direction and frequency of the land point excursion, as shown in Fig. 4 , and make histogram of the total offset of the land point, as shown in Fig. 5. The information statistics steps at intervals of $1 \mathrm{~min}, 3 \mathrm{~h}$, and $24 \mathrm{~h}$ are the same as those that are separated by $4 \mathrm{~h}$, and statistical analysis of the error distribution of land offsets is performed.

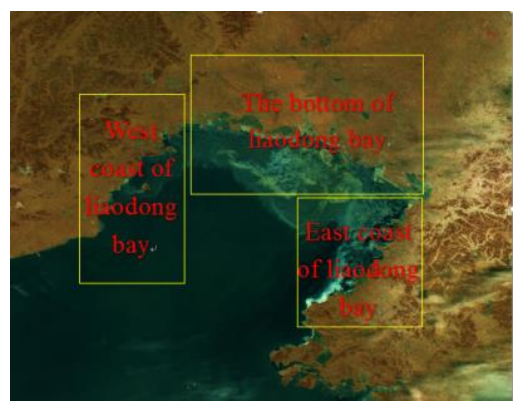

Figure 3 Three areas of Liaodong Bay

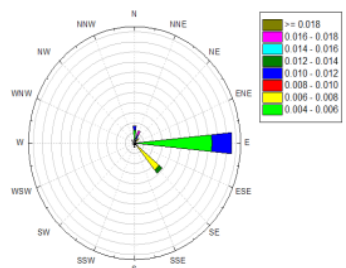

(a)The bottom of Liaodong Bay

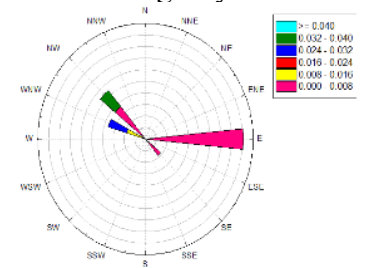

(b)The west bank of Liaodong Bay 


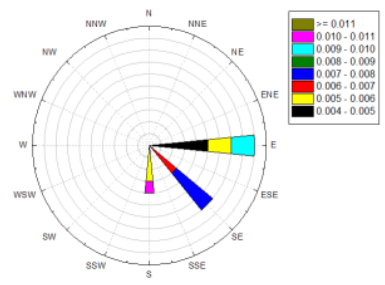

(c)East coast of Liaodong Bay

Figure 4 Rose diagram of land point offset in Liaodong Bay, four hours apar

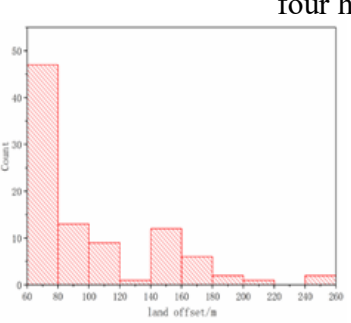

(a)The bottom of Liaodong Bay

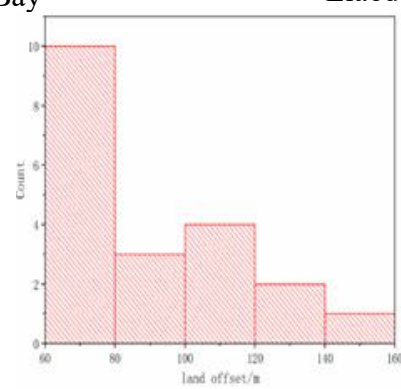

(c)The east coast of Liaodong Bay

Figure 5 Histogram of the offset of the land points in Liaodong Bay, four hours apart.

The offset direction and offsets of land points in three areas of Liaodong Bay at different time intervals are shown in the Table 4 and Table 5.

Through statistical analysis, it can be seen that: when the time interval is 4 hours and 24 hours, the dominant migration direction in the three regions in Liaodong bay is east; when the time interval is 1 minute, the dominant migration direction in Liaodong Bay bottom and Liaodong Bay west coast land is south, followed by east and southeast respectively; the dominant migration in Liaodong Bay East Coast is north, followed by east; When the time interval is 3 hours, the dominant migration direction in west of Liaodong Bay, bottom of Liaodong Bay and east of Liaodong bay are east, west and south respectively, followed by southeast, east, southeast respectively. The land offset in three regions is major centralized distribution in a range which is from $60 \mathrm{~m}$ to $80 \mathrm{~m}$. That is to say, the offset of land is basically equal to 1.2 times of pixels, and the maximum land offset is less than 2 times of pixels.

Table 4 Offset direction of land points in Liaodong Bay at different time intervals

\begin{tabular}{cccc}
\hline $\begin{array}{c}\text { The time } \\
\text { interval }\end{array}$ & $\begin{array}{c}\text { The west } \\
\text { bank of } \\
\text { Liaodong } \\
\text { Bay }\end{array}$ & $\begin{array}{c}\text { The } \\
\text { bottom of } \\
\text { Liaodong } \\
\text { Bay }\end{array}$ & $\begin{array}{c}\text { The east } \\
\text { coast of } \\
\text { Liaodong } \\
\text { Bay }\end{array}$ \\
\hline 1 min & S & S & N \\
$3 \mathrm{~h}$ & W & E & S \\
$4 \mathrm{~h}$ & E & E & E \\
$24 h$ & E & E & E \\
\hline
\end{tabular}

Table 5 Offsets of land points in Liaodong Bay at different time intervals

\begin{tabular}{|c|c|c|c|c|}
\hline Area & $\begin{array}{l}\text { The interval of } 1 \\
\text { min }\end{array}$ & The interval of $3 \mathrm{~h}$ & The interval of $4 \mathrm{~h}$ & The interval of $24 \mathrm{~h}$ \\
\hline $\begin{array}{l}\text { The bottom of } \\
\text { Liaodong Bay }\end{array}$ & $0-100$ meters & $0-100$ meters & $60-80$ meters & $70-80$ meters \\
\hline $\begin{array}{l}\text { The east coast of } \\
\text { Liaodong Bay }\end{array}$ & $65-75$ meters & $60-80$ meters & $60-80$ meters & $70-80$ meters \\
\hline $\begin{array}{c}\text { The west bank of } \\
\text { Liaodong Bay }\end{array}$ & $0-100$ meters & $0-100$ meters & $50-100$ meters & $70-80$ meters \\
\hline
\end{tabular}

\section{CONCLUSION AND DISCUSSION}

On December 29, 2015, the launch of the GF-4 satellite provided a new type of data source for remote sensing monitoring of sea ice drift. The "High Score 4" satellite has the characteristics of high temporal resolution of geostationary satellites, and is more efficient in obtaining effective national data. It can provide data support for high-precision monitoring of sea ice's rapid drift. To accurately quantify the tracking error of GF-4 image to sea ice drift, we used the 28 images which are acquired from GF-4 between August.2016 to March.2018 to correction, registration and mathematical statistics. And we analyzed the direction, angle and offset of land points in three areas of Liaodong Bay during the different time intervals.

By statistical analysis of the datasets which have time interval of $1 \mathrm{~min} 、 3 \mathrm{~h} 、 4 \mathrm{~h}$ and $24 \mathrm{~h}$ respectively. We found that the direction of the offset of land points in Liaodong bay are usually east, some of land points are southeast, other direction could be ignored. Furthermore, the quantity of the offset would not change much, and stay around the size of two pixels with the increase in time interval. This research result allows us to have a deeper understanding of the error of GF4 satellite image tracking of sea ice drift, and it also paves the way for the study of sea ice drift behind.

GF-4 satellites are mainly used for military purposes rather than civilian use. Therefore, although the revisiting cycle of GF-4 satellite is 20 seconds, it is not collected every 20 seconds. And GF-4 satellite imagery with good weather, high visibility, and cloudlessness should be selected as experimental data. At present, there are few data sources with a time interval of 3 hours, and there may 
be errors in the error analysis of 3 hours interval, which still needs further study. In addition, it is necessary to strengthen coordination with polar-orbiting satellites in data acquisition and application in order to increase the application range and efficiency of GF-4 satellite data.

\section{ACKNOWLEDGMENT}

Thanks to the GF-4 satellite data provided by the China Centre for Resources Satellite Data and Application (http://www.cresda.com) and the DEM correction data provided by the Geospatial Data Cloud (http://www.gscloud.cn/search).

\section{REFERENCES}

1. F.G.Ardhuin and R.Ezraty.Enhanced "Arctic sea ice dnft estimation merging radiometer and scatterometer data " IEEE Transactions on Geoscience and Remote Sensing, 2012, 50(7): 2639-2648.

2. Haarpaintner J. "Arctic-wide operational sea ice drift from enhanced- resolution QuikScat SeaWinds scatterometry and its validation," IEEE Transactions on Geoscience and Remote Sensing, 2006, 44(1): 102-107.I. S. Jacobs and C. P. Bean, "Fine particles, thin films and exchange anisotropy," in Magnetism, vol. III, G. T. Rado and H. Suhl, Eds. New York: Academic, 1963, pp. 271-350.

3. Lavergne T.et al."Sea ice motion from low-resolution satellite sensors: An altemative method and its validation in the Arctic ," Joumal of Geophysical Research: Oceans (1978-2012), 2010, 115(C10).

4. Liu A. K. and Zhao Y. H. "Arctic sea ice drift from wavelet analysis of NSCAT and special sensor microwave imager data ," Journal of Geophysical Research, 1999, 104(C5): 529-538.Y. Yorozu, M. Hirano, K. Oka, and Y. Tagawa, "Electron spectroscopy studies on magneto-optical media and plastic substrate interface," IEEE Transl. J. Magn. Japan, vol. 2, pp. 740-741, August 1987 [Digests 9th Annual Conf. Magnetics Japan, p. 301, 1982].

5. M.Zhao Y.,Liu A. K., and Long D. G. "Validation of sea ice motion from QuikSCAT with those from SSM/I and buoy," IEEE Transactions on Geoscience and Remote Sensing, 2002, 40(6): 1241-1246.

6. Yao L.B,Liu Y and Wu Y.Z. "Ship target tracking based on gaofen-4 satellite," High resolution ground observation academic conference.2017.

7. Wang Z.T,Zhang Y.H and Yuan S.Y. "Land aerosols in beijing-tianjin-hebei region were monitored by gaofen-4 data," Environment and sustainable development. 2016, 41(5):113-116.

8. S.Su J and Shi P.J, " Features of seaice disaster in the Bohai Sea in 2010," Journal of natural disaster, 2011,20 (6):87-93.

9. Ji Y.G,"Ice typical features retrieval in Liaodong Bay based on microwave remote sensing imagery,"
Doctoral dissertation, institute of oceanography, Chinese academy of sciences, 2006.

10. Fan Y.D and Wu W, "GF-4 launched successfully to help disaster prevention and reduction," China's disaster reduction, 2016,2:48-49. 